\title{
Ischemic Penumbra: A Personal View
}

\author{
Stephen M. Davis Geoffrey A. Donnan \\ Departments of Medicine and Neurology, Melbourne Brain Centre at the Royal Melbourne Hospital, University of \\ Melbourne, Victoria, VIC, Australia
}

\section{Keywords}

Penumbra $\cdot$ Ischemic stroke $\cdot$ Imaging

\begin{abstract}
The concept of the ischemic penumbra was defined over 40 years ago by Lindsay Symon and his group and is now an established principle of all acute ischemic stroke therapies. These reperfusion treatments rescue threatened, critically hypoperfused brain tissue and have been proven to improve clinical outcomes.

We have been fortunate to have observed and played a small part in the penumbral story from its beginnings in the $1970 \mathrm{~s}$ to its pivotal position today. Over this period, we have witnessed penumbral imaging evolve from positron emission tomography through to magnetic resonance imaging and now predominantly computed tomography perfusion, with the advent of automated imaging facilitating case selection for reperfusion therapies.

We and others have conducted clinical trials using penumbral imaging to extend the time window for intravenous thrombolysis and select patients for thrombectomy. Together with the concept of fast- and slow-growing ischemic infarct patterns, this embeds the penumbral principle in everyday clinical management. The opportunity now exists to make penumbral imaging even more portable, affordable, and more widely available using mobile platforms, novel imaging techniques, digital linkage, and artificial intelligence.
\end{abstract}

(c) 2021 S. Karger AG, Basel

karger@karger.com

(c) 2021 S. Karger AG, Basel

www.karger.com/ced

Karger!

\section{The Beginnings}

We both began our training in neurology in 1976. Little did we realize that this was such a pivotal time in the history of stroke which had several thousand years of a history of therapeutic nihilism. When we were interns, stroke was still called "CVA," appropriately named "confused vascular analysis" by one of the stroke pioneers, Vladimir Hachinski (Fig. 1). The referring doctor in the Emergency Department would apologize for admitting a stroke patient and say that the next one would be "more interesting." Stroke units were in their infancy with one of the first acute units established at Sunnybrook Hospital in Toronto, Canada, by Norris and Hachinski [1], enabled by a generous philanthropic donation $[1,2]$.

Computed tomography (CT) started to be introduced as a routine imaging tool in the mid-1970s. Even then, most strokes were looked after by general physicians with little interest or expertise and who did not regard brain imaging as a priority. Indeed, it was not uncommon to be challenged if a CT was ordered for stroke diagnosis "because it will not alter the outcome."

During our training as neurologists from 1977 to 1980, we first heard of the concept of the ischemic penumbra [3]. This was quite a revolutionary concept that acute stroke was an evolving process, with definition of cerebral blood flow thresholds for reversible and irreversible cerebral ischemia. This dynamic process showed progressive 


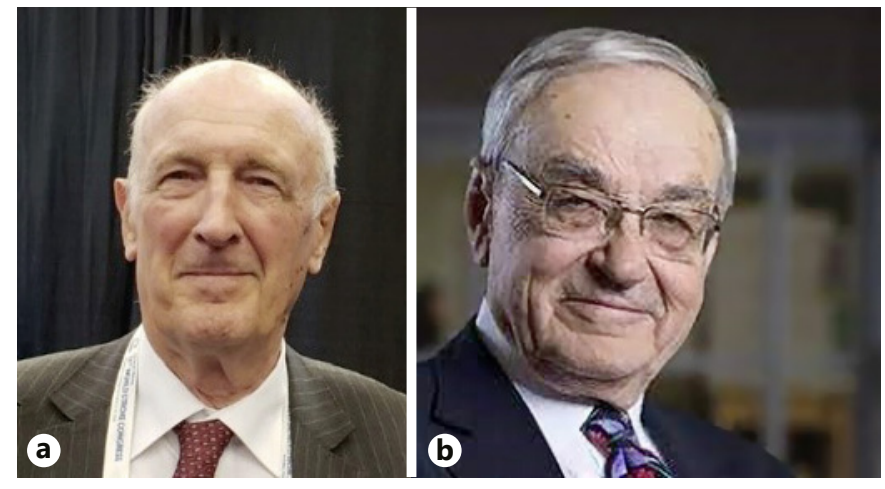

Fig. 1. John Norris (a) and Vladimir Hachinski (b) who established the world's first acute stroke unit at Sunnybrook, Toronto, Canada, in 1976 [1].

cerebral ischemic damage over an uncertain period of time. Prior to this, the firm dogma was that immediate brain tissue death occurred after stroke onset, with no opportunity for intervention. However, led by Lindsay Symon, a professor of neurosurgery at the National Hospital for Neurology and Neurosurgery in Queen Square, UK, this concept was completely overturned [4] (Fig. 2). He introduced the term "penumbra" which he apparently coined while walking with a colleague, Anthony Strong, across Guildford Street to have lunch at Queen Square [5]. He stated that it was "rather like the area around the centre of a candle flame where there is a small bright zone known as the penumbra." Astrup and Lassen pointed out that it was also akin to the bright zone around the sun in a total eclipse [5].

Working with other outstanding scientists including visiting neurosurgeons from Denmark, Jens Astrup, and Sweden, Bo Siesjö, he performed pivotal animal experiments to demonstrate the time course of tissue death in relation to perfusion thresholds in baboons [6]. They were able to show that this region of cerebral dysfunction could be monitored by somatosensory-evoked potentials which could be restored to normal with restoration of cerebral blood flow [3]. At around this time, Jones et al. [7] also established the important relationship between thresholds of cerebral ischemia and duration of vessel occlusion in an awake primate model.

Surprisingly, the enormity of their discoveries were not really appreciated at the time; perhaps, in part, this reflected the perception that Lindsay Symon was primarily a neurosurgeon and not actively treating acute ischemic stroke. Furthermore, there was no emergency department at the National Hospital and little management

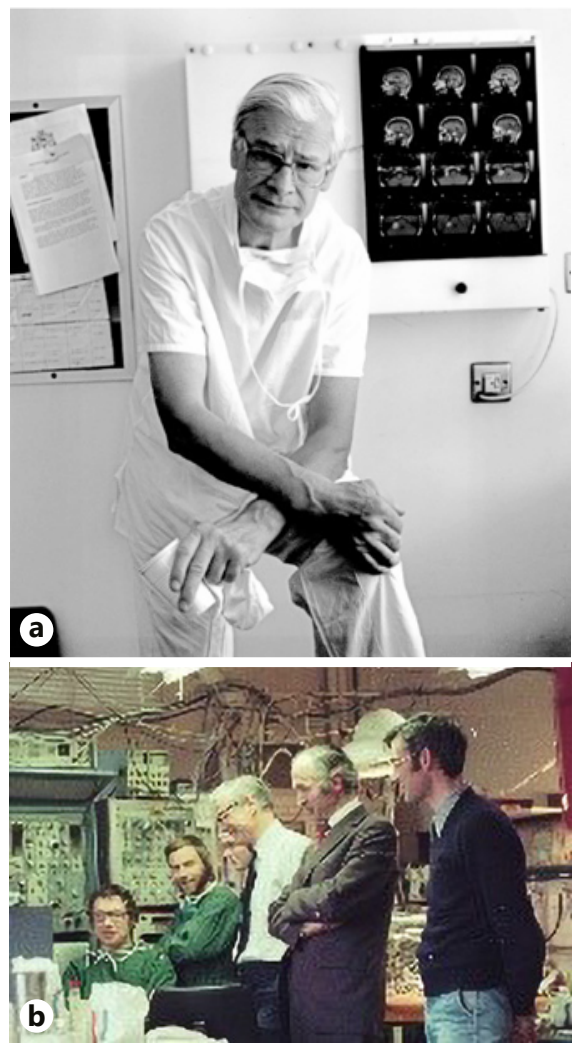

Fig. 2. Lindsay Symon (a) with his research team (b). Left to right: Neil Branston, Terry Hope, Robert Harris, Lindsay Symon, Anthony Strong, and Jens Astrup [5].

of acute stroke. Interestingly, another leading neurosurgeon, Thor Sundt at the Mayo Clinic, a friend and colleague of Lindsay Symon, demonstrated reversibility of cerebral ischemia in humans with subarachnoid hemorrhage monitored by changes in somatosensory-evoked potentials $[8,9]$. Lindsay Symon and his group prophesized that therapeutic intervention to restore brain perfusion would potentially be based, in the future, on imaging of the penumbra [6].

\section{Early Penumbral Imaging Experiences Using Positron Emission Tomography}

In the early 1980s, we were both stroke research fellows at the Massachusetts General Hospital working with Robert Ackerman, who had appointments in both the Departments of Radiology and Neurology. The MGH stroke service was the home of $\mathrm{C}$ Miller Fisher who is widely recognized as one of the fathers of modern stroke medi- 

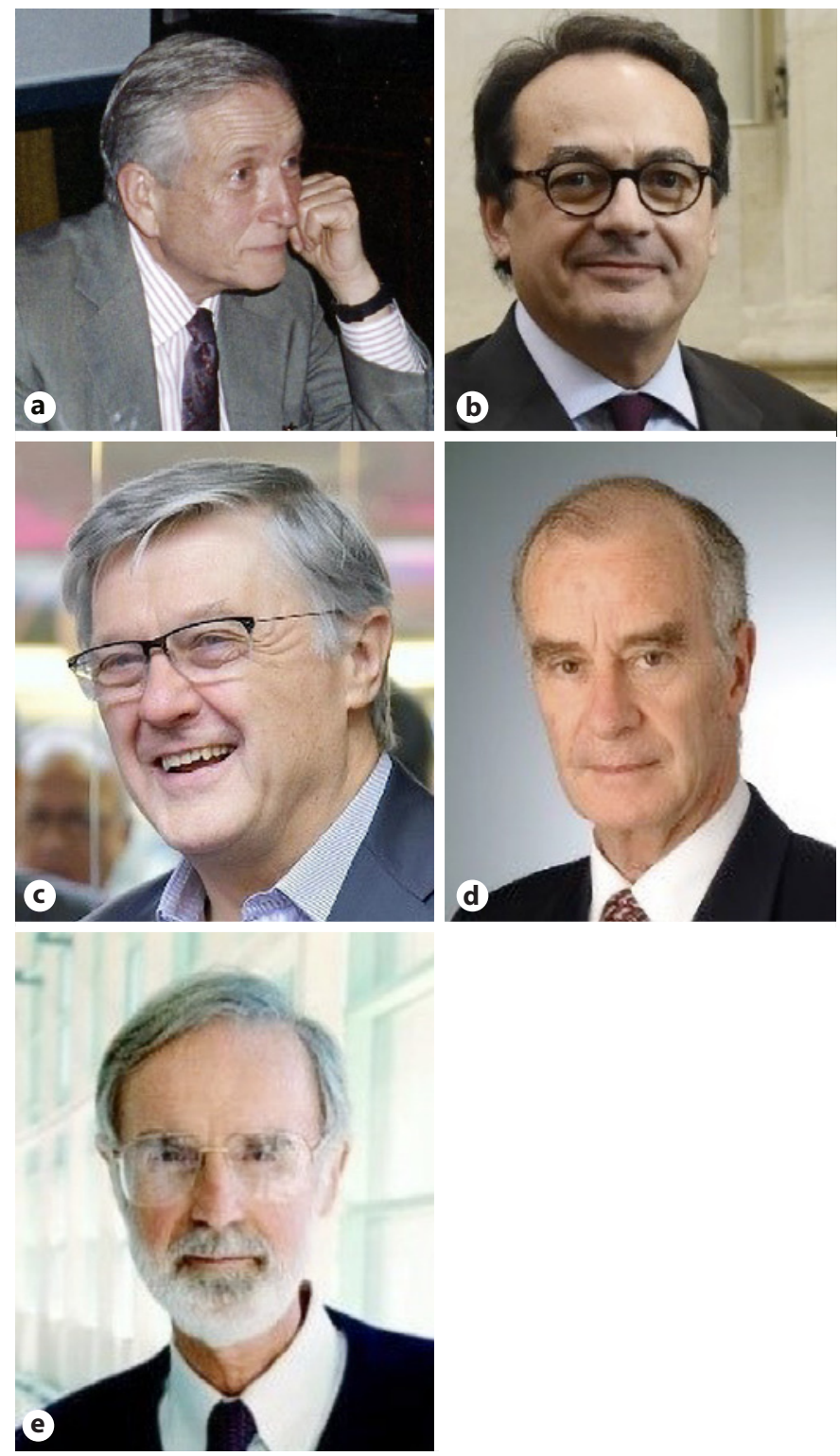

Fig. 3. Some of the early pioneers of the ischemic penumbra using PET technology. Robert Ackerman (a), Jean-Claude Baron (b), Richard Frackowiak (c), Wolf-Dieter Heiss (d), and Marcus Raichle (e). PET, positron emission tomography.

cine. Ackerman et al. [10] led the positron emission tomography (PET) program at the MGH, one of the early pioneering programs of its type, underpinned by a large NIH grant. The main focus of the research group was acute ischemic stroke (Fig. 3).

They demonstrated that increased oxygen extraction fraction signified potentially salvageable tissue (Fig. 4). There were also other PET programs launched around the same time in St Louis, led by Marcus Raichle [11], and

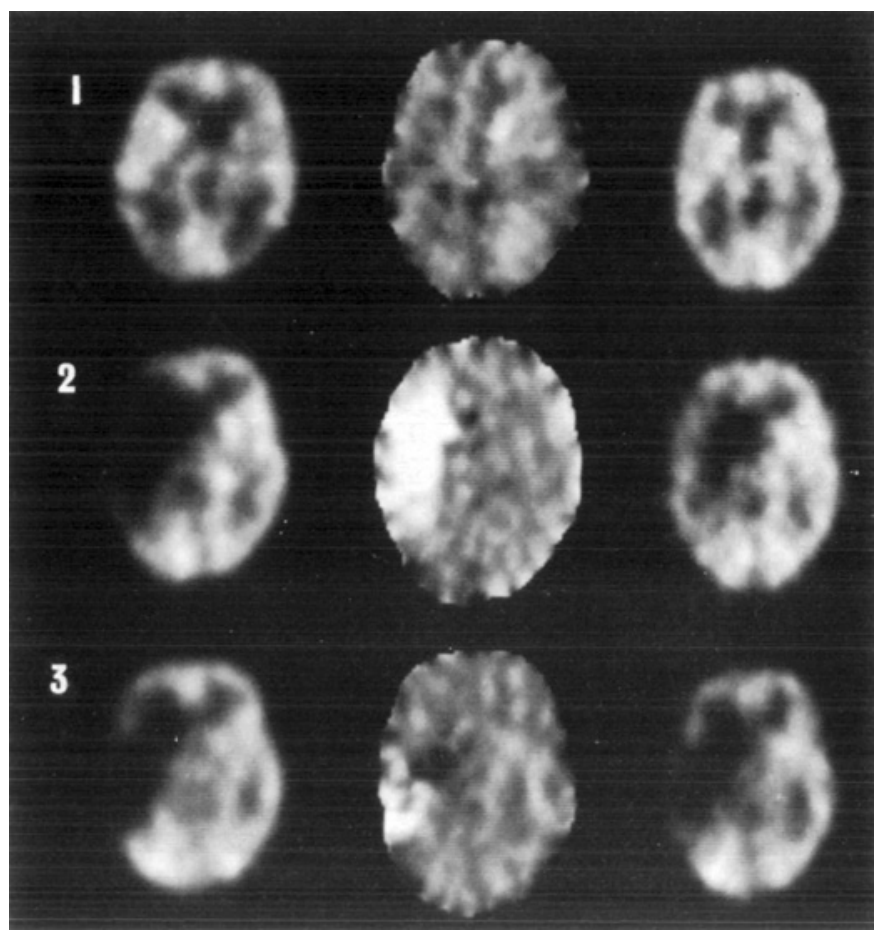

Fig. 4. Initial PET images at three levels $(1,2,3)$ from the Frackowiak Group [13] showing the ischemic penumbra represented by increased oxygen extraction fraction (lower two central panels, white signal), reduced CBF (lower two left panels) and relatively maintained $\mathrm{CMRO}_{2}$ (lower two right panels). PET, positron emission tomography.

in London by Terry Jones and Richard Frackowiak (Fig. 3) $[12,13]$.

Jean-Claude Baron had been Ackerman's first research fellow at the MGH several years before (Fig. 3). Jim Grotta, another stroke pioneer, was also an early Ackerman research fellow. Upon his return to France, Baron led the PET program in Paris for many years and later in Caen. He coined the term "misery perfusion" as the penumbral signature and the inverse of the concept of "luxury perfusion" devised earlier by Niels Lassen [14] using more basic arterial perfusion measures with ${ }^{133}$ xenon $[15,16]$. He and others showed that penumbral salvage directly predicts neurological recovery [17].

How to reperfuse hypoperfused tissue with a consequent increased oxygen extraction fraction was a topic of debate. An early hypothesis was to increase systemic blood pressure, but this has never been fully explored with large randomized control trials, despite pilot studies confirming feasibility [18]. The more direct idea of recanalization of occluded major arteries was not really on 


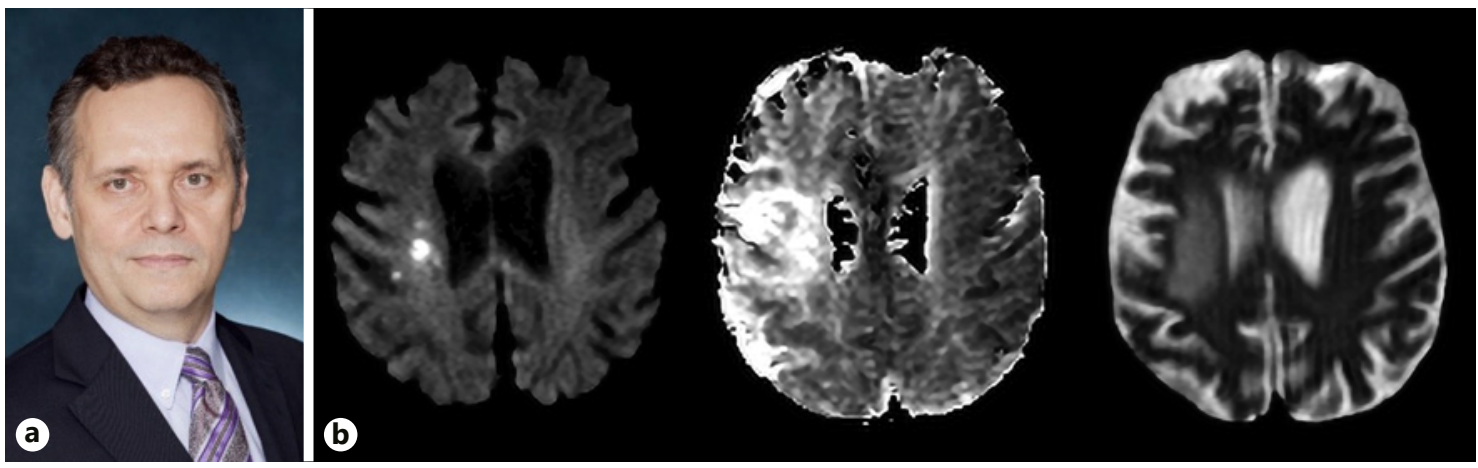

Fig. 5. Steven Warach (a). A mismatch acutely (b) between the region of hypoperfusion (middle image, larger) and the region of diffusion abnormality (left image, smaller) is predictive of ischemic lesion enlargement (right image), regardless of time from onset [38].

the horizon at this early stage, particularly as early trials of thrombolysis were negative [19]. However, Meyer et al. [20] had attempted surgical embolectomy as early as the late 1970s and early 1980s.

We both recall the excitement of seeing the first images in humans of the ischemic penumbra on PET as defined by reduced $\mathrm{CBF}$ and increased oxygen extraction fraction (Fig. 4). To reverse this process seemed to be a pipe dream. Indeed, to even consider that there would be an approved effective therapy during our careers seemed most unlikely. Remarkably, this hypothesis has been now completely validated.

The brain CT scanner was invented 50 years ago by Hounsfield (winning the Nobel Prize) and still remains the workhorse of acute stroke imaging [21]. It is exquisitely sensitive in the distinction between ischemic stroke and intracerebral hemorrhage, the essential substrate before considering thrombolytic therapy. Magnetic resonance imaging (MRI) only became widely available a decade later, invented by Damadian, Mansfield, and Lauterbur, although only the latter 2 were awarded the Nobel Prize amid considerable controversy [22-24]. MRI ushered in the revolution of contemporary penumbral imaging.

\section{The Penumbral Imaging Revolution}

As mentioned earlier, the ${ }^{15} \mathrm{O}$ PET technique was shown to demonstrate the penumbra by an increase in oxygen extraction fraction in animal and human models $[13,16,25,26]$. Based on their delineation of a reversible ischemic state, potentially amenable to therapy, a number of investigators suggested that their findings would have important stroke management and selection for therapeutic trials $[13,16,25,27]$. There were a number of other PET techniques which added to the penumbral story including glucose CBF mismatch, flumazenil/CBF mismatch [28], and ${ }^{18} \mathrm{~F}-\mathrm{MISO}$ [29]. However, none of these were ever practical in everyday clinical use. As a collective, these studies shed enormous light on the natural history and evolution of the ischemic penumbra over the passage of time. Remarkably, they illustrated the opportunities for acute intervention, but also showed the persistence of the penumbra for prolonged time intervals up to $24-48 \mathrm{~h}[30-33]$.

Using single-photon emission CT, earlier studies showed the predictive value of acute hypoperfusion and reperfusion [34-36]. It was possible to evaluate the influence of thrombolytic therapy on regions of depressed cerebral blood flow. However, standard single-photon emission CT techniques such as HMPAO only monitored blood flow and could not image the penumbra per se.

The real revolution in practical penumbral imaging came with the advent of MRI [37]. Warach showed that the mismatch between a larger perfusion region and a smaller diffusion core was a useful measure of the penumbra [38] (Fig. 5). A further important step was the introduction of thresholding for cerebral perfusion. Specifically, the accuracy was improved when limits for core and salvageable tissue were introduced. This was important particularly to exclude benign oligemia, a problem with earlier use of $T_{\max } 2 \mathrm{~s}[39,40]$. Subsequently, $T_{\max } 6$ $s$ was shown to optimize the penumbral threshold [41]. This was previously validated against PET [42]. Also, thresholding with acute diffusion coefficient values was 
important in defining the damaged ischemic core which was generally irreversible. However, partial salvage of the core defined by acute diffusion coefficient values could be generated by hyperacute reperfusion [43]. Later work by the combined EPITHET and DEFUSE collaborators indicated that sustained, clinically relevant reversal of the acute diffusion lesion was infrequent [44].

We and others described the different patterns of diffusion perfusion match and mismatch on MRI and their potential therapeutic applications [45-47]. Because MR perfusion is more difficult to obtain, there was a push to use the mismatch between clinical stroke severity (NIH Stroke Score and the DWI lesion as a surrogate measure of the penumbra $[48,49])$. Interestingly, this concept has been successfully used in recent trials of penumbral selection and reperfusion at later time windows with both CTP and MRI (clinical/core mismatch) [50,51].

Very quickly after MR became established as a clinically useful means of identifying the penumbra, a return to the earlier described technique of CT perfusion was validated by Wintermark et al. [52-54]. Groups led by Parsons and Campbell performed comparisons between MRI and CTP, showing that the different techniques provided analogous clinical information about core and penumbra [55]. In particular, the infarct core was identified by a thresholded cerebral blood volume and later cerebral blood flow, generally $<30 \%$ of the homologous region [56]. CT perfusion thresholding mirrored the MRI approach. As per MRI, use of $T_{\max } 6 \mathrm{~s}$ has been shown to be optimal in definition of the penumbra [57].

A number of studies showed that the information provided by these 2 very different brain imaging techniques was comparable. CTP had the advantage of being more universally available, cheaper, faster, and more userfriendly, although less obvious to the naked eye than DWI [58]. Earlier, some concerns about renal damage from gadolinium were dispelled [59].

CTP remains the most commonly used method for routine penumbral imaging, although some centers still employ acute MRI techniques. Indeed, in many countries, the use of CTP has become a routine part of acute stroke management, often replacing simple noncontrast CT scanning alone (Fig. 6).

\section{The Therapeutic Revolution}

The sheer logic of recanalizing major arteries to reperfuse the ischemic penumbra with thrombolytic agents had been considered for some time, particularly influ-

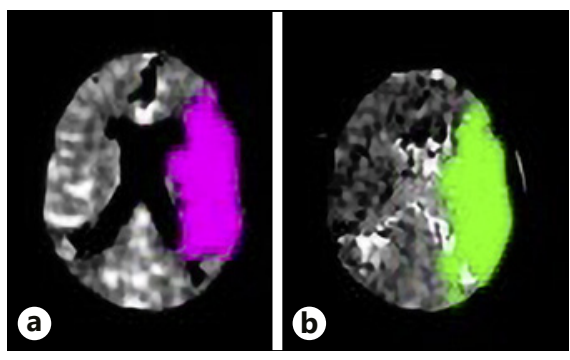

Fig. 6. CTP images showing large ischemic core in the left panel (a) documented by $\mathrm{CBF}<30 \%$ of contralateral side. Right panel (b) shows perfusion lesion thresholded $\mathrm{T} \max 6$. There is significant mismatch between a lesion core and perfusion, but uncertainty exists as to whether reperfusion therapies should be used in these circumstances.

enced by the successful cardiac paradigm. Imaging had brought it to the forefront given that a specific ischemic stroke diagnosis could be made. There were early attempts with intra-arterial and intravenous agents, including a number with streptokinases which were unsuccessful [60-62]. The remarkable success with ultra-early intravenous tissue plasminogen activator (tPA) was the breakthrough in 1995 [63]. For the first time, stroke was shown to be treatable and this had a major impact on the prevailing therapeutic nihilism, the proliferation of stroke units, and the movement of stroke management into "prime time."

The importance of time in the therapeutic equation was emphasized by our own Australian streptokinase trial and the early tPA trials including NINDS and the ECASS trials [63-67]. This led to the concept that "time is brain" proposed by Camilo Gomez and readily explained by studies showing that the frequency of the ischemic penumbra diminishes with time $[31,68]$. It is important to emphasize that all these earlier trials relied on clinical criteria and noncontrast CT alone.

Interestingly, there was a "mismatch" between our evolving understandings of the duration of the ischemic penumbra, probably up to $24-48 \mathrm{~h}$ in some cases versus the relatively short 4.5 - $\mathrm{h}$ window for thrombolytic therapy $[31-33,69]$. A similar developmental sequence occurred with thrombectomy as with tPA, early failure followed by spectacular success. The turning point was the advent of much better intra-arterial clot retrieval devices, the first of which was the Solitaire stent retriever. We recall the excitement at the World Stroke Congress in Istanbul in 2014 when the MR CLEAN results were presented to a standing ovation, a phenomenon never experienced 


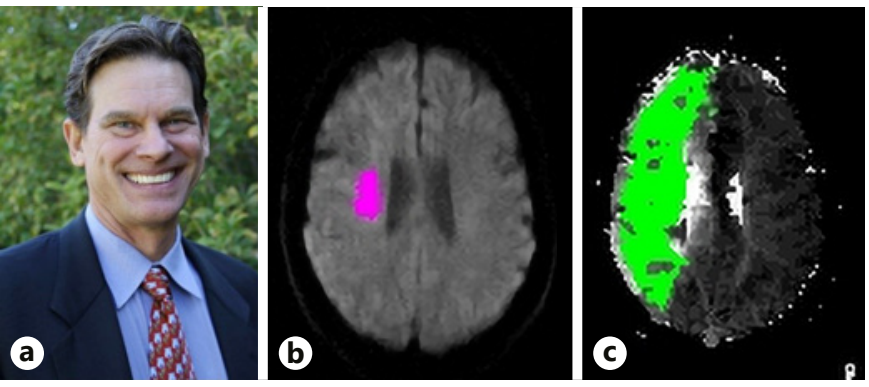

Fig. 7. Greg Albers (a). Image on left (b) shows MRI DWI lesion and on right (c) thresholded perfusion image $\left(T_{\max }>6\right)$ using RAPID ${ }^{j}$ software (iSchemaView). The DWI lesion reflects the mostly irreversible ischemic core, and the mismatch with the larger perfusion lesion reflects tissue at risk. MRI, magnetic resonance imaging.

in our careers [70]. There were 5 initial strongly positive thrombectomy trials which led to rapid change in clinical guidelines worldwide [70-74]. The most positive results were seen in those trials employing penumbral selection to enrich the trial population to those most likely to respond [73]. However, debate has continued concerning the role of penumbral selection given that thrombectomy was also shown to be positive in the trials using CT angiography and simple noncontrast CT selection criteria [70]. With a number needed to treat 2.6 to reduce disability based on the meta-analysis of the pivotal thrombectomy trials, it is obvious that thrombectomy is one of the most powerful interventions in medicine [75]. These initial trials generally used a 6-h time window based largely upon the efficacy of intravenous therapy up to almost this time.

The stage was set to extend the time window using multimodal imaging. However, this only became feasible with the advent of automated techniques.

\section{Automated Imaging}

Real-time imaging of the ischemic penumbra with thresholded values was pioneered by the Stanford group using their RAPID software [76, 77] (Fig. 7). A number of others followed, using a color-coded system which made interpretation simple, rapid, and generalizable [78]. This imaging allowed urgent assessment of the amount of salvageable tissue and the size of the ischemic core.

Ischemic Penumbra: A Personal View
Meta-analysis of the thrombectomy trials showed that large ischemic cores predicted worse clinical outcome, although benefit was still achieved at upper limits even with core sizes of over $100 \mathrm{~mL}$ [79]. The benefits and risks of reperfusion of patients with large core sizes remain controversial and under investigation in a number of clinical trials.

\section{Selection for Therapy and Extended Time Windows}

\section{Intravenous Thrombolysis}

The disparity between the short 4.5-h therapeutic time window shown in the intravenous thrombolytic therapy trials and the longer duration of the ischemic penumbra in some patients set the scene for imaging selection to be used in later time windows. Rocha and Jovin, and later Albers (Fig. 7), popularized the concept of fast- and slow-growing infarct cores which had been previously demonstrated with PET $[27,80,81]$. This explained the disparity and fitted well with the overall penumbral hypothesis.

We conducted the first randomized controlled trial (EPITHET) to extend the time window beyond 3 and then $4.5 \mathrm{~h}$ using tPA [40]. Automated imaging had not yet been introduced, and we therefore retrospectively tested our hypothesis of penumbral selection for treatment responders. Although it did not reach significance, we showed that in patients with the penumbra using MRI, reperfusion was strongly associated with improved clinical outcomes. Further, in patients with co-registered images or using the $T_{\max } 6$ threshold (rather than $T_{\max } 2$ employed in the trial) post hoc positive results were obtained [82].

This set the scene for our extended time window trial (EXTEND) using automated imaging selection of patients with adequate penumbra using either MRI or CT $[77,83]$. We aimed to double the time window to $9 \mathrm{~h}$ and include "wake-up" stroke patients. The positive result further validated the penumbral hypothesis with prolonged time windows and in patients with an uncertain time of onset. It further prompted the question, "should even longer time windows be considered"? Whether the penumbral concept could be applied to stroke of uncertain time of onset, including wake-up stroke, also needed to be determined. Another approach, not specifically penumbral selection, used the concept of mismatch of DWI-FLAIR. This alternative approach identified patients within $4.5 \mathrm{~h}$ and was substantiated in the WAKEUP trial [84]. 
Thrombectomy at Extended Time Windows

A further major change in clinical practice then occurred following the positive results of 2 pivotal extended time window thrombectomy trials, based on penumbral selection. DAWN used a clinical/core mismatch selection criteria to show efficacy of clot retrieval to $24 \mathrm{~h}$ [51]. Likewise, DEFUSE-3 showed efficacy up to $16 \mathrm{~h}$ using the classical DWI/PWI mismatch technique [50]. Further validating penumbral selection as a principle, these trials showed that the benefits of reperfusion in late time windows were at least as great as those treated earlier. Indeed, small series have even suggested the use of thrombectomy beyond $24 \mathrm{~h}$ in patients with persisting penumbra [85]. Clinical trials are likely.

\section{Where to Now?}

Based on our understanding of the temporal evolution of the ischemic penumbra, the proportion of penumbral tissue after stroke onset rapidly declines from near $100 \%$ to lower levels depending on factors such as collateral supply and the consequent speed of growth of the ischemic core. The classic time-efficacy curve of tPA commenced at $1 \mathrm{~h}$ because very few patients were treated in the first $60 \mathrm{~min}$ [86]. This relationship was emphasized by the greater benefit shown among the initial 90min cohort of the NINDS trial than in the subsequent 90-180 cohort [63]. This led to the later concept of prehospital stroke treatment and the "golden hour," the first hour after stroke onset [87]. The prehospital mobile stroke unit (MSU) paradigm was pioneered by Faßbender, with Walter, in Homburg, Germany [8890], later by Audebert and Ebinger et al. [91] in Berlin, and Grotta in the USA [92]. Initial studies including our own Melbourne MSU showed that a 10-fold greater number of patients could be treated within the "golden hour" [93]. Further, this approach was found to be costeffective [94]. This has now translated into proven increases in clinical outcomes in 2 pivotal phase 3 clinical trials in Europe (B_PROUD) and the USA (BEST-MSU), which should lead to change in clinical guidelines worldwide $[95,96]$.

The weight of current CT scanners used in MSU limits their deployment. To date, for example, although there is no aircraft application, plans are underway in Australia [97-99]. Nearly, all metropolitan MSUs around the world deploy a half-ton CT scanner and currently do not utilize penumbral imaging. There is an opportunity to develop lighter weight and more sophisticated CT imaging devices capable of giving penumbral measures useful for therapeutic intervention [100].
While CT and MR with perfusion capability remain the standard imaging technique for penumbral selection, there are a number of newer imaging techniques which may provide similar information. These have the potential advantages of being extremely lightweight, hence highly portable and much more affordable. Examples include electromagnetic radiation and new MR techniques [101].

Coupled with the aforementioned developments in new imaging techniques may be more sophisticated artificial intelligence approaches to interpreting the prognostic value of penumbral signatures [100]. These could prove invaluable in more remote settings where there will be reliance on telemedicine. The opportunity for prolonged real-time penumbral monitoring may also exist.

Telemedicine is transforming the triage and management of acute stroke patients, particularly in nonmetropolitan settings [102-104]. Penumbral imaging may well become an integral component of "telestroke." Linking these technologies is another exciting development, telerobotic thrombectomy [105]. This addresses the critical shortage of expert interventional neuroradiologists outside of comprehensive stroke centers in cities. An integral component of this will be an online assessment of penumbral status as a part of the thrombectomy process.

In conclusion, we have been fortunate to have been witness to and played a small part in what could be termed the penumbral revolution $[106,107]$. The prediction of Lindsay Symon that the penumbra could be imaged in real time and form the basis for therapeutic intervention has been thoroughly validated. There is no doubt it will continue to form the basis of therapeutic decisions in acute ischemic stroke. The digital revolution will take imaging of the penumbra to another level; who knows what the next 40 years will bring!

\section{Acknowledgments}

This work was published in the Celebration of the 30th Anniversary of the inception of Cerebrovascular Diseases 1991-2021.

\section{Statement of Ethics}

Written informed consent was obtained for the use of all images, except Figure 2, of Lindsay Symon who is deceased and whose next of kin is unknown. The image provided is a true and accurate representation of Lindsay Symon. 


\section{Conflict of Interest Statement}

The authors have no conflicts of interest to declare.

\section{Funding Sources}

There were no relevant funding sources.

\section{Author Contributions}

Both authors contributed equally to the manuscript.

\section{Data Availability Statement}

All relevant data are freely available upon request.

\section{References}

1 Norris JW, Hachinski VC. Intensive care management of stroke patients. Stroke. 1976; 7:573-7.

2 Hachinski V, Bornstein NM, Markus HS John W Norris 1933-2020. Stroke. 2020;51: 1913-5.

3 Astrup J, Symon L, Branston NM, Lassen NA. Cortical evoked potential and extracellular $\mathrm{K}+$ and $\mathrm{H}+$ at critical levels of brain ischemia. Stroke. 1977;8:51-7.

4 Baron JC, Markus HS, Pickard JD, Davis SM, Donnan GA. Lindsay symon: a giant of stroke. Int J Stroke. 2020;15:356-60.

5 Symon L. The ischemic penumbra - the beginning. In: Donnan GA, Baron JC, Davis SM, Sharpe FR, editors. The Ischemic Penumbra. Informa Healthcare $\odot$, Reproduced by permission of Taylor and Francis Group, LLC, a division of Informa plc; 2007. p. 1-6.

6 Astrup J, Siesjö BK, Symon L. Thresholds in cerebral ischemia - the ischemic penumbra. Stroke. 1981;12:723-5.

7 Jones TH, Morawetz RB, Crowell RM, Marcoux FW, FitzGibbon SJ, DeGirolami U, et al. Thresholds of focal cerebral ischemia in awake monkeys. J Neurosurg. 1981;54:77382.

8 Symon L. Disordered cerebro-vascular physiology in aneurysmal subarachnoid haemorrhage. Acta Neurochirurgica. 1978;41:7-22.

9 Sundt TM Jr, Grant WC, Garcia JH. Restoration of middle cerebral artery flow in experimental infarction. J Neurosurg. 1969;31:31121.

10 Ackerman RH, Correia JA, Alpert NM, Baron JC, Gouliamos A, Grotta JC, et al. Positron imaging in ischemic stroke disease using compounds labeled with oxygen 15 . Initial results of clinicophysiologic correlations. Arch Neurol. 1981;38:537-43.

11 Powers WJ, Raichle ME. Positron emission tomography and its application to the study of cerebrovascular disease in man. Stroke. 1985;16:361-76.

12 Frackowiak RS, Lenzi GL, Jones T, Heather JD. Quantitative measurement of regional cerebral blood flow and oxygen metabolism in man using $15 \mathrm{O}$ and positron emission tomography: theory, procedure, and normal values. J Comput Assist Tomogr. 1980;4:727-36.

13 Wise RJ, Bernardi S, Frackowiak RS, Legg NJ, Jones T. Serial observations on the patho- physiology of acute stroke. The transition from ischaemia to infarction as reflected in regional oxygen extraction. Brain. 1983; 106(Pt 1): 197-222.

14 Lassen NA. The luxury-perfusion syndrome and its possible relation to acute metabolic acidosis localised within the brain. Lancet. 1966;288:1113-5.

15 Baron JC, Bousser MG, Rey A, Guillard A, Comar D, Castaigne P. Reversal of focal "misery-perfusion syndrome" by extra-intracranial arterial bypass in hemodynamic cerebral ischemia. A case study with 150 positron emission tomography. Stroke. 1981;12:454-9.

16 Baron JC, Bousser MG, Comar D, Soussaline F, Castaigne P. Noninvasive tomographic study of cerebral blood flow and oxygen metabolism in vivo. Potentials, limitations, and clinical applications in cerebral ischemic disorders. Eur Neurol. 1981;20:273-84.

17 Furlan M, Marchal G, Viader F, Derlon JM, Baron JC. Spontaneous neurological recovery after stroke and the fate of the ischemic penumbra. Ann Neurol. 1996;40:216-26.

18 Rordorf G, Koroshetz WJ, Ezzeddine MA, Segal AZ, Buonanno FS. A pilot study of druginduced hypertension for treatment of acute stroke. Neurology. 2001;56:1210-3.

19 Meyer JS, Gilroy J, Barnhart MI, Johnson JF. Anticoagulants plus streptokinase therapy in progressive stroke. JAMA. 1964;189:373.

20 Meyer FB, Piepgras DG, Sundt TM Jr, Yanagihara T. Emergency embolectomy for acute embolic occlusion of the middle cerebral artery. Clin Neurosurg. 1985;32:155-73.

21 Hounsfield GN. Historical notes on computerized axial tomography. J Can Assoc Radiol. 1976;27:135-42.

22 Damadian R. Tumor detection by nuclear magnetic resonance. Science. 1971;171:1151-3.

23 Lauterbur PC. Image formation by induced local interactions. Examples employing nuclear magnetic resonance. Nature. 1973;242: 190-1.

24 Dreizen P. The nobel prize for MRI: a wonderful discovery and a sad controversy. Lancet. 2004;363:78

25 Heiss WD, Graf R, Wienhard K, Löttgen J, Saito R, Fujita T, et al. Dynamic penumbra demonstrated by sequential multitracer PET after middle cerebral artery occlusion in cats. J Cereb Blood Flow Metab. 1994;14:892-902.
26 Touzani O, Young AR, Derlon JM, Beaudouin V, Marchal G, Rioux P, et al. Sequential studies of severely hypometabolic tissue volumes after permanent middle cerebral artery occlusion. A positron emission tomographic investigation in anesthetized baboons. Stroke. 1995;26:2112-9.

27 Marchal G, Serrati C, Rioux P, Petit-Taboué MC, Viader F, de la Sayette V, et al. PET imaging of cerebral perfusion and oxygen consumption in acute ischaemic stroke: relation to outcome. Lancet. 1993;341:925-7.

28 Heiss WD, Kracht LW, Thiel A, Grond M, Pawlik G. Penumbral probability thresholds of cortical flumazenil binding and blood flow predicting tissue outcome in patients with cerebral ischaemia. Brain. 2001;124:20-9.

29 Read SJ, Hirano T, Abbott DF, Sachinidis JI, Tochon-Danguy HJ, Chan JG, et al. Identifying hypoxic tissue after acute ischemic stroke using PET and 18F-fluoromisonidazole. Neurology. 1998;51:1617-21.

30 Marchal G, Beaudouin V, Rioux P, de la Sayette V, Le Doze F, Viader F, et al. Prolonged persistence of substantial volumes of potentially viable brain tissue after stroke: a correlative PET-CT study with voxel-based data analysis. Stroke. 1996;27:599-606.

31 Darby DG, Barber PA, Gerraty RP, Desmond PM, Yang Q, Parsons M, et al. Pathophysiological topography of acute ischemia by combined diffusion-weighted and perfusion MRI. Stroke. 1999;30:2043-52.

32 Read SJ, Hirano T, Abbott DF, Markus R, Sachinidis JI, Tochon-Danguy HJ, et al. The fate of hypoxic tissue on 18F-fluoromisonidazole positron emission tomography after ischemic stroke. Ann Neurol. 2000;48:228-35.

33 Markus R, Reutens DC, Kazui S, Read S, Wright P, Pearce DC, et al. Hypoxic tissue in ischaemic stroke: persistence and clinical consequences of spontaneous survival. Brain. 2004;127:1427-36.

34 Davis SM, Chua MG, Lichtenstein M, Rossiter SC, Binns D, Hopper JL. Cerebral hypoperfusion in stroke prognosis and brain recovery. Stroke. 1993;24:1691-6.

35 Baird AE, Donnan GA, Austin MC, Fitt GJ, Davis SM, McKay WJ. Reperfusion after thrombolytic therapy in ischemic stroke measured by single-photon emission computed tomography. Stroke. 1994;25:79-85. 
36 Grotta JC, Alexandrov AV. tPA-associated reperfusion after acute stroke demonstrated by SPECT. Stroke. 1998;29:429-32.

37 Warach S, Gaa J, Siewert B, Wielopolski P, Edelman RR. Acute human stroke studied by whole brain echo planar diffusion-weighted magnetic resonance imaging. Ann Neurol. 1995;37:231-41.

38 Baird AE, Benfield A, Schlaug G, Siewert B, Lövblad KO, Edelman RR, et al. Enlargement of human cerebral ischemic lesion volumes measured by diffusion-weighted magnetic resonance imaging. Ann Neurol. 1997;41: 581-9.

39 Albers GW, Thijs VN, Wechsler L, Kemp S, Schlaug G, Skalabrin E, et al. Magnetic resonance imaging profiles predict clinical response to early reperfusion: the diffusion and perfusion imaging evaluation for understanding stroke evolution (DEFUSE) study. Ann Neurol. 2006;60:508-17.

40 Davis SM, Donnan GA, Parsons MW, Levi C, Butcher KS, Peeters A, et al. Effects of alteplase beyond $3 \mathrm{~h}$ after stroke in the echoplanar imaging thrombolytic evaluation trial (EPITHET): a placebo-controlled randomised trial. Lancet Neurol. 2008;7:299309.

41 Olivot JM, Mlynash M, Thijs VN, Kemp S, Lansberg MG, Wechsler L, et al. Optimal Tmax threshold for predicting penumbral tissue in acute stroke. Stroke. 2009;40:469-75.

42 Takasawa M, Jones PS, Guadagno JV, Christensen S, Fryer TD, Harding S, et al. How reliable is perfusion MR in acute stroke? Validation and determination of the penumbra threshold against quantitative PET. Stroke. 2008;39:870-7.

43 Kidwell CS, Saver JL, Mattiello J, Starkman S, Vinuela F, Duckwiler G, et al. Thrombolytic reversal of acute human cerebral ischemic injury shown by diffusion/perfusion magnetic resonance imaging. Ann Neurol. 2000;47: 462-9.

44 Campbell BC, Purushotham A, Christensen S, Desmond PM, Nagakane Y, Parsons MW, et al. The infarct core is well represented by the acute diffusion lesion: sustained reversal is infrequent. J Cereb Blood Flow Metab. 2012;32:50-6.

45 Schwamm LH, Koroshetz WJ, Sorensen AG, Wang B, Copen WA, Budzik R, et al. Time course of lesion development in patients with acute stroke: serial diffusion- and hemodynamic-weighted magnetic resonance imaging. Stroke. 1998;29:2268-76.

46 Barber PA, Darby DG, Desmond PM, Yang Q, Gerraty RP, Jolley D, et al. Prediction of stroke outcome with echoplanar perfusionand diffusion-weighted MRI. Neurology. 1998;51:418-26.

$47 \mathrm{Ma} \mathrm{H}$, Zavala JA, Teoh H, Churilov L, Gunawan M, Ly J, et al. Fragmentation of the classical magnetic resonance mismatch "penumbral" pattern with time. Stroke. 2009;40: $3752-7$.
48 Davalos A, Blanco M, Pedraza S, LeiraR, CastellanosM,Pumar JM,et al. The clinicalDWI mismatch: a new diagnostic approach to the brain tissue at risk of infarction. Neurology. 2004;62:2187-92.

49 Prosser J, Butcher K, Allport L, Parsons M, MacGregor L, Desmond P, et al. Clinical-diffusion mismatch predicts the putative penumbra with high specificity. Stroke. 2005;36: $1700-4$.

50 Albers GW, Marks MP, Kemp S, Christensen S, Tsai JP, Ortega-Gutierrez S, et al. Thrombectomy for stroke at 6 to 16 hours with selection by perfusion imaging. $\mathrm{N}$ Engl J Med. 2018;378:708-18.

51 Nogueira RG, Jadhav AP, Haussen DC, Bonafe A, Budzik RF, Bhuva P, et al. Thrombectomy 6 to 24 hours after stroke with a mismatch between deficit and infarct. N Engl Med. 2018;378:11-21.

52 Eastwood JD, Lev MH, Wintermark M, Fitzek C, Barboriak DP, Delong DM, et al. Correlation of early dynamic CT perfusion imaging with whole-brain MR diffusion and perfusion imaging in acute hemispheric stroke. Am J Neuroradiol. 2003;24:1869-75.

53 Wintermark M, Meuli R, Browaeys P, Reichhart M, Bogousslavsky J, Schnyder P, et al. Comparison of CT perfusion and angiography and MRI in selecting stroke patients for acute treatment. Neurology. 2007;68:694-7.

54 Wintermark M, Flanders AE, Velthuis B, Meuli R, van Leeuwen M, Goldsher D, et al. Perfusion-CT assessment of infarct core and penumbra: receiver operating characteristic curve analysis in 130 patients suspected of acute hemispheric stroke. Stroke. 2006;37: 979-85.

55 Bivard A, Spratt N, Levi C, Parsons M. Perfusion computer tomography: imaging and clinical validation in acute ischaemic stroke. Brain. 2011;134:3408-16.

56 Campbell BC, Christensen S, Levi CR, Desmond PM, Donnan GA, Davis SM, et al. Cerebral blood flow is the optimal CT perfusion parameter for assessing infarct core. Stroke. 2011;42:3435-40.

57 Campbell BC, Christensen S, Levi CR, Desmond PM, Donnan GA, Davis SM, et al. Comparison of computed tomography perfusion and magnetic resonance imaging perfusion-diffusion mismatch in ischemic stroke. Stroke. 2012;43:2648-53.

58 Vagal A, Wintermark M, Nael K, Bivard A, Parsons M, Grossman AW, et al. Automated CT perfusion imaging for acute ischemic stroke: pearls and pitfalls for real-world use. Neurology. 2019;93:888-98.

59 Ang TE, Bivard A, Levi C, Ma H, Hsu CY, Campbell B, et al. Multi-modal CT in acute stroke: wait for a serum creatinine before giving intravenous contrast? No! Int J Stroke. 2015;10:1014-7.
60 Candelise L, Aritzu E, Ciccone A, Ricci S, Wardlaw J, Tognoni G, et al. Randomised controlled trial of streptokinase, aspirin, and combination of both in treatment of acute ischaemic stroke. Multicentre acute stroke trial: Italy (MAST-I) Group. Lancet 1995;346: 1509-14.

61 Donnan GA, Davis SM, Chambers BR, Gates PC, Hankey GJ, McNeil JJ, et al. Streptokinase for acute ischemic stroke with relationship to time of administration: Australian Streptokinase (ASK) Trial Study Group. JAMA. 1996; 276:961-6.

62 Multicenter Acute Stroke Trial-Europe Study Group, Hommel M, Cornu C, Boutitie F, Boissel JP. Thrombolytic therapy with streptokinase in acute ischemic stroke. N Engl J Med. 1996;335:145-50.

63 National Institute of Neurological Disorders, Stroke rt-PA Stroke Study Group. Tissue plasminogen activator for acute ischemic stroke. N Engl J Med. 1995;333(24):1581-7.

64 Donnan GA, Davis SM, Chambers BR, Gates PC, Hankey GJ, McNeil JJ, et al. Streptokinase for acute ischemic stroke with relationship to time of administration: Australian Streptokinase (ASK) Trial Study Group. JAMA. 1996; 276:961-6.

65 Hacke W, Kaste M, Fieschi C, Toni D, Lesaffre $\mathrm{E}$, von Kummer R, et al. Intravenous thrombolysis with recombinant tissue plasminogen activator for acute hemispheric stroke. The European Cooperative Acute Stroke Study (ECASS). JAMA. 1995;274:1017-25.

66 Hacke W, Kaste M, Fieschi C, von Kummer R, Davalos A, Meier D, et al. Randomised double-blind placebo-controlled trial of thrombolytic therapy with intravenous alteplase in acute ischaemic stroke (ECASS II). Second European-Australasian Acute Stroke Study investigators. Lancet. 1998;352:124551.

67 Hacke W, Kaste M, Bluhmki E, Brozman M, Dávalos A, Guidetti D, et al. Thrombolysis with alteplase 3 to 4.5 hours after acute ischemic stroke. N Engl J Med. 2008;359:1317-29.

68 Gomez CR. Editorial: time is brain! J Stroke Cerebrovasc Dis. 1993;3:1-2.

69 Heiss WD, Kracht LW, Thiel A, Grond M, Pawlik G. Penumbral probability thresholds of cortical flumazenil binding and blood flow predicting tissue outcome in patients with cerebral ischaemia. Brain. 2001;124:20-9.

70 Berkhemer OA, Fransen PS, Beumer D, van den Berg LA, Lingsma HF, Yoo AJ, et al. A randomized trial of intraarterial treatment for acute ischemic stroke. N Engl J Med. 2015; 372:11-20

71 Goyal M, Demchuk AM, Menon BK, Eesa M, Rempel JL, Thornton J, et al. Randomized assessment of rapid endovascular treatment of ischemic stroke. N Engl J Med. 2015;372: 1019-30.

72 Saver JL, Goyal M, Bonafe A, Diener HC, Levy EI, Pereira VM, et al. Stent-retriever thrombectomy after intravenous t-PA vs. t-PA alone in stroke. N Engl J Med. 2015;372:2285-95. 
73 Campbell BC, Mitchell PJ, Kleinig TJ, Dewey HM, Churilov L, Yassi N, et al. Endovascular therapy for ischemic stroke with perfusionimaging selection. N Engl J Med. 2015;372: 1009-18.

74 Jovin TG, Chamorro A, Cobo E, de Miquel MA, Molina CA, Rovira A, et al. Thrombectomy within 8 hours after symptom onset in ischemic stroke. N Engl J Med. 2015;372: 2296-306.

75 Goyal M, Menon BK, van Zwam WH, Dippel DW, Mitchell PJ, Demchuk AM, et al. Endovascular thrombectomy after large-vessel ischaemic stroke: a meta-analysis of individual patient data from five randomised trials. Lancet. 2016;387:1723-31.

76 Straka M, Albers GW, Bammer R. Real-time diffusion-perfusion mismatch analysis in acute stroke. J Magn Reson Imaging. 2010;32: 1024-37.

77 Lansberg MG, Lee J, Christensen S, Straka M, De Silva DA, Mlynash M, et al. RAPID automated patient selection for reperfusion therapy: a pooled analysis of the echoplanar imaging thrombolytic evaluation trial (EPITHET) and the Diffusion and Perfusion Imaging Evaluation for Understanding Stroke Evolution (DEFUSE) Study. Stroke. 2011;42:160814.

78 Churilov L, Liu D, Ma H, Christensen S, Nagakane Y, Campbell B, et al. Multiattribute selection of acute stroke imaging software platform for extending the time for thrombolysis in emergency neurological deficits (EXTEND) clinical trial. Int J Stroke. 2013;8:20410.

79 Campbell BCV, Majoie CBLM, Albers GW, Menon BK, Yassi N, Sharma G, et al. Penumbral imaging and functional outcome in patients with anterior circulation ischaemic stroke treated with endovascular thrombectomy versus medical therapy: a meta-analysis of individual patient-level data. Lancet Neurol. 2019;18:46-55.

80 Rocha M, Jovin TG. Fast versus slow progressors of infarct growth in large vessel occlusion stroke: clinical and research implications. Stroke. 2017;48:2621-7.

81 Albers GW. Late window paradox. Stroke. 2018;49:768-71.

82 Nagakane Y, Christensen S, Brekenfeld C, Ma $\mathrm{H}$, Churilov L, Parsons MW, et al. EPITHET: positive result after reanalysis using baseline diffusion-weighted imaging/perfusionweighted imaging co-registration. Stroke. 2011;42:59-64

$83 \mathrm{Ma} \mathrm{H}$, Campbell BCV, Parsons MW, Churilov L, Levi CR, Hsu C, et al. Thrombolysis guided by perfusion imaging up to 9 hours after onset of stroke. N Engl J Med. 2019;380 1795-803.
84 Thomalla G, Simonsen CZ, Boutitie F, Andersen G, Berthezene Y, Cheng B, et al. MRIguided thrombolysis for stroke with unknown time of onset. N Engl J Med. 2018;379: 611-22.

85 Sarraj A, Mlynash M, Heit J, Pujara D, Lansberg M, Marks M, et al. Clinical outcomes and identification of patients with persistent penumbral profiles beyond 24 hours from last known well: analysis from DEFUSE 3. Stroke. 2021;52(3):838-49.

86 Emberson J, Lees KR, Lyden P, Blackwell L, Albers G, Bluhmki E, et al. Effect of treatment delay, age, and stroke severity on the effects of intravenous thrombolysis with alteplase for acute ischaemic stroke: a meta-analysis of individual patient data from randomised trials. Lancet. 2014;384:1929-35.

87 Saver JL, Smith EE, Fonarow GC, ReevesMJ, ZhaoX, OlsonDM, et al. The "golden hour" and acute brain ischemia: presenting features and lytic therapy in $>30,000$ patients arriving within 60 minutes of stroke onset. Stroke. 2010;41:1431-9.

88 Fassbender K, Walter S, Liu Y, Muehlhauser F, Ragoschke A, Kuehl S, et al. "Mobile stroke unit" for hyperacute stroke treatment. Stroke. 2003;34:e44.

89 Walter S, Kostopoulos P, Haass A, Keller I, Lesmeister M, Schlechtriemen T, et al. Diagnosis and treatment of patients with stroke in a mobile stroke unit versus in hospital: a randomised controlled trial. Lancet Neurol. 2012;11:397-404.

90 Fassbender K, Grotta JC, Walter S, Grunwald IQ, Ragoschke-Schumm A, Saver JL. Mobile stroke units for prehospital thrombolysis, triage, and beyond: benefits and challenges. Lancet Neurol. 2017;16:227-37.

91 Ebinger M, Winter B, Wendt M, Weber JE, Waldschmidt C, Rozanski M, et al. Effect of the use of ambulance-based thrombolysis on time to thrombolysis in acute ischemic stroke: a randomized clinical trial. JAMA. 2014;311: 1622-31.

92 Rajan SS, Baraniuk S, Parker S, Wu TC, Bowry $\mathrm{R}$, Grotta JC. Implementing a mobile stroke unit program in the United States: why, how, and how much? JAMA Neurol. 2015;72:229-34.

93 Zhao H, Coote S, Easton D, Langenberg F, Stephenson M, Smith K, et al. Melbourne mobile stroke unit and reperfusion therapy: greater clinical impact of thrombectomy than thrombolysis. Stroke. 2020;51:922-30.

94 Kim J, Easton D, Zhao H, Coote S, Sookram G, Smith K, et al. Economic evaluation of the melbourne mobile stroke unit. Int J Stroke. 2021;16(4):466-75.
95 Ebinger M, Siegerink B, Kunz A, Wendt M, Weber JE, Schwabauer E, et al. Association between dispatch of mobile stroke units and functional outcomes among patients with acute ischemic stroke in Berlin. JAMA. 2021; 325(5):454-66.

96 Grotta JC, Yamal JM, Parker SA, Rajan SS, Gonzales NR, Jones WL, et al. Benefits of stroke treatment delivered by a mobile stroke unit compared to standard management by emergency medical services (BESTMSU Study). N Engl J Med. 2021;385(11): 971-81.

97 Walter S, Zhao H, Easton D, Bil C, Sauer J, Liu Y, et al. Air-mobile stroke unit for access to stroke treatment in rural regions. Int J Stroke. 2018;13:568-75.

98 Gardiner FW, Bishop L, Dos Santos A, Sharma P, Easton D, Quinlan F, et al. Aeromedical retrieval for stroke in Australia. Cerebrovasc Dis. 2020;49:334-40.

99 Walter S, Fassbender K, Easton D, SchwarzM, GardinerFW, LangenbergF, et al. Stroke care equity in rural and remote areas - novel strategies. Vessel Plus. 2021;5:27.

100 Mouridsen K, Thurner P, Zaharchuk G. Artificial intelligence applications in stroke. Stroke. 2020;51:2573-9.

101 Walsh KB. Non-invasive sensor technology for prehospital stroke diagnosis: current status and future directions. Int J Stroke. 2019; 14:592-602.

102 Bladin CF, Cadilhac DA. Effect of telestroke on emergent stroke care and stroke outcomes. Stroke. 2014;45:1876-80.

103 Cadilhac DA, Sheppard L, Kim J, Tan E, Gao L, Sookram G, et al. Economic evaluation protocol and statistical analysis plan for the cost-effectiveness of a novel Australian stroke telemedicine program; the victorian stroke telemedicine (VST) program. Front Neurol. 2020;11:602044.

104 Wilcock AD, Schwamm LH, Zubizarreta JR Zachrison KS, Uscher-Pines L, Richard JV, et al. Reperfusion treatment and stroke outcomes in hospitals with telestroke capacity. JAMA Neurol. 2021;78(5):527-35.

105 Beaman CB, Kaneko N, Meyers PM, Tateshima S. A review of robotic interventional neuroradiology. Am J Neuroradiol. 2021; 42(5):808-14.

106 Ermine CM, Bivard A, Parsons MW, Baron JC. The ischemic penumbra: from concept to reality. Int J Stroke. 2021;16:497-509.

107 Baron JC. The core/penumbra model: implications for acute stroke treatment and patient selection in 2021. Eur J Neurol. 2021; 28(8):2794-803. 